\title{
Ameloblastoma: Case Report
}

\author{
Isaque Toledo Zimmermann* and Milena Bortolotto Felippe Silva \\ Department of Dentistry, Brazil \\ *Corresponding Author: Isaque Toledo Zimmermann, Department of Dentistry, \\ Brazil.
}

Received: January 31, 2020

Published: April 27, 2020

(C) All rights are reserved by Isaque Toledo

Zimmermann and Milena Bortolotto

Felippe Silva.

\begin{abstract}
Ameloblastomas are rare odontogenic tumors of the jaws, more frequently found in mandible. Etiology, clinical and histological behavior and various modality of treatment has been extensively discussed. Conservative treatment sometimes associated to additional procedures has been used as a good option for many treatments of this tumor. The present article has for objective describe a case of ameloblastoma of jaw treated by conservative methods where jaw fracture occurred as a complication of this initial therapeutics.
\end{abstract}

Keywords: Ameloblastoma; Conservative Treatment; Cryotherapy; Jaw Fracture

\section{Introduction}

Ameloblastomas are benign tumors of odontogenic origin and constitute approximately $1 \%$ of all maxillary tumors [1-7]. Clinically they are characterized by slow growth, absence of pain, and expansion involving bone and leading to facial deformities that slow down the diagnosis. This lesion occurs most commonly in the mandible, especially in molars in the region of-angle ram, and with less frequency in the jaw.

The origin of ameloblastoma is still controversial, but dental blade theory has been more accepted than enamel organ, epithelial remains, basal cells of the epithelial surface and the epithelium of odontogenic cysts [8,9]. According to Csiba., et al. [10] many causal etiological factors have to be proposed, including: a) nonspecific irritant factors such as exodontias, caries, trauma, infections, inflammations or dental eruption: b) diseases caused by nutritional deficiencies and c) viral pathogenesis. Diagnosis is often given on a routine examination, since lesions are asymptomatic and can cause loss or tooth resorptions expansion of jaws [11-14].

The literature has classified ameloblastomas into uncysticistic, solid or multicystic, peripheral and malignant subtypes [9,1517]. The uncystic type is defined as an intramural lesion or intraluminal epithelial proliferation with microscopic ameloblastic characteristics and occurs in 10 to $15 \%$ of cases. It is more frequent in the jaw during the third decade of life and seems to have a less aggressive clinical behavior and a better prognosis than solid ameloblastoma [8,18]. Radiographically, it appears as a welldemarcated radiolucent uni or multilocular area, associated or not with the presence of retained tooth [5].

The solid or multicystic variant occurs in $85 \%$ of cases, is usually asymptomatic, during its growth can reabsorb roots of teeth [14]. Regarding radiographic findings, they present multilocular radiolucent aspect, with an image classically known as "soap bubbles" or "honeycombs", in dependence on the size of these lesions being large or small, respectively.

They may also present a unilocular aspect and may confuse the professional with a cystic lesion, although on its margins, it is mostly an irregular border $[9,14]$. The peripheral type occurs in soft tissues, is quite rare and affects $1 \%$ of cases, clinically there is a presence of pain and ulcerated sessile or pediculated lesion in the gums or alveolar mucosa, can be clinically confused with fibroma. Some authors report that they originate from the odontogenic epithelium below or within the basal layer of the oral mucosa $[9,13,14]$.

The therapeutic objective of any extirpative surgical procedure is to remove the entire lesion and not leave cells that may cause recurrence of the lesion. The methods used to achieve these goals vary widely and depend on the nature of the pathological condition of the lesion in question [19]. Ameloblastomas are treated by curet, curettage and enucleation, or radical surgery [20]. 
Jaw ameloblastomas should be treated as radically as possible. However, ameloblastomas that appear radiographically as unilocular lesions can be treated conservatively (i.e. enucleation or curettage, or both) when all areas of cystic lumen are wanted to be controlled in the trans operative period.

Supraperiosteal resection of the bone is necessary when a tenuous extension or perforation in the cortical is noted [21]. According to Nastri., et al. [22] the treatment modalities of ameloblastoma include chemotherapy, electrocautery, cryosurgery, radiotherapy, use of sclerosing agents, curettage and radical block excision, such as hemimandibulectomy. Nakamura., et al. [6] proposes marsupialization as an initial step in the treatment of unicystic ameloblastoma. After adequate tumor decompression, enucleation can be made and consequently, complications associated with the most sensitive techniques can be avoided.

However, some lesions become more invasive after marsupialization [23]. The most important thing in choosing treatment is the aggressiveness of the lesion. Other factors that should be evaluated prior to surgery are anatomical location of the lesion, its bone confinement, duration of the lesion, and possible reconstruction methods after surgery [24].

Gardner [25] and Atkinson and Harwood [15] mention that some authors have treated ameloblastoma exclusively with radiotherapy or is in association with chemotherapy. Conservative approaches, such as enucleation and curettage, have shown recurrences with $90 \%$ rates in the jaw and $100 \%$ in the maxilla [26]. A radical approach consists of total or partial maxillectomy or resection, with or without defect of continuity in the jaw. This type of treatment has increased recurrence rates of ameloblastomas, but create severe cosmetic, functional and reconstructive damage [8].

Cryosurgery has been a treatment modality for ameloblastomas and other locally invasive dental bone lesions $[27,28]$. The goal of cryosurgery is to eliminate invasive bone injury without necessarily involving the problems of radical conventional surgery. Consequently, the use of extremely low temperatures allows the treatment of ameloblastomas devitalizing bone in situ and maintaining the organic matrix [8]. There are four basic methods of cryotherapy that can be used in the maxillofacial region: probe, gel soluble water probe, spiraling liquid nitrogen and spray liquid nitrogen. Each technique has its advantages and disadvantages, but probe with gel soluble water and liquid nitrogen spray are the most used. Nitrogen spray is the most potent and fastest method, that reaches the temperature of $-198^{\circ} \mathrm{C}$ in a few minutes. It can be used to treat large and irregular cavities, but care should be taken to avoid necrosis in adjacent soft tissues [8]. The possible postoperative complications of cryosurgery in the bone are: formation of sequestration, pathological fracture, dehiscence and edema [27-29]. Pathological fractures and kidnappings after cryosurgery have been prevented with the use of autogenous bone graft in the cavity [30].

\section{Case Report}

A 51-year-old female patient natural from Campinas/SP was referred to Mario Gatti Hospital in November 2002 by her dentist, who initially detected the lesion as a small increase in intraoral volume in the region of right mandibular angle extending to the body region and a lateral radiography of the jaw was requested (Figure 1).

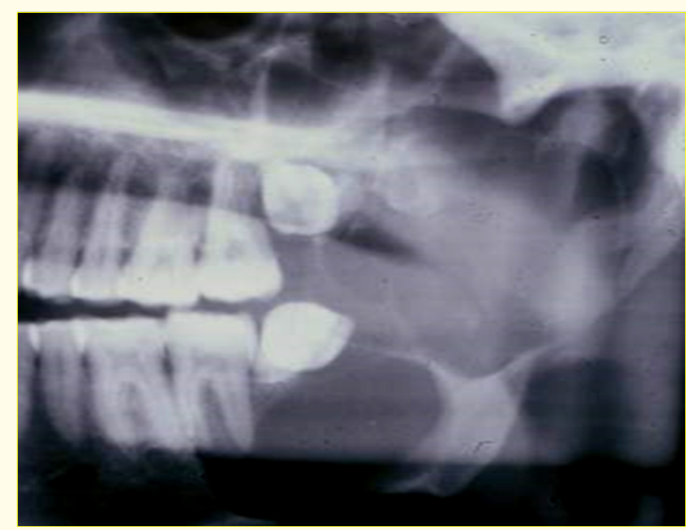

Figure 1: Mandibula Lateral Radiography. Source: Dr. Thais Christina Emidio.

Clinically intraoral asymmetry and mild-oral asymmetry. On radiographic examination, the presence of extensive unilocular radiotransparent lesion was observed. Also, in November incisional biopsy of the lesion was performed, in an outpatient environment under local anesthesia and the material sent to the pathology laboratory.

The result of anatomopathological examination was ameloblastoma. The proposed treatment was the enucleation of the lesion followed by cryotherapy. This treatment modality was proposed in order to avoid more extensive surgery with loss of bone structure, avoid a skin incision and consequent scar. In December 2002, the lesion was cured followed by the application of liquid nitrogen at the site. These procedures were performed in a hospital environment under general anesthesia. Intraoral incision was made in the area of angle of the mandible in order to expose the lesion, 


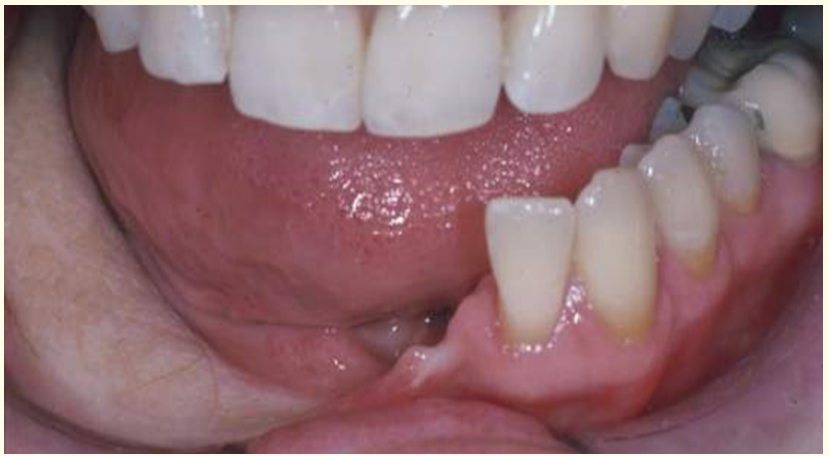

Figure 2: Increase in intraoral volume.

Source: Dr. Thais Emidio.

curettage was performed, which consists of surgical scraping of the cavity wall in hard or soft tissue to remove its contents, also preserving bone continuity. Soon after, the application of spray nitrogen was performed, for this, the adjacent tissues with gauze were previously isolated, and nitrogen was applied to the lesion performing three applications of one minute each, with intervals of five minutes between them. After that the insulation was removed and sutured at simple points. What is desired with the use of liquid nitrogen is the devitalization of the remaining bone at the site of the lesion.

The patient evolved well in the immediate postoperative period, being recommended a mild diet and ice compress at the site. About 90 days after curettage, the patient reported discomfort in the region characterized by the presence of pain and purulent infection, the patient associated the onset of these symptoms with crepitation during the chewing of more registry foods. A panoramic radiography was requested and fractured jaw. On the same day maxillo-mandibular block was made with Erich bar to stabilize the fragments. In view of this, a new procedure for installation of reconstruction plate for the fixation of these fragments was proposed. This time extraoral incision was performed in the area of angle of the mandible in order to facilitate access in order to place reconstruction plate; during this procedure material was removed from the edges of the fracture and was sent for anatomic-pathological examination and no lesion was observed in the fragments. Forty implants were also installed in order to rehabilitate the patient, returning chewing, for this was made a prosthesis with support of the bar/clip type.

In the postoperative period, anti-inflammatory drugs were prescribed for five days and antibiotics for seven days. Follow-up was performed every 6 months for a period of 2 years and did not

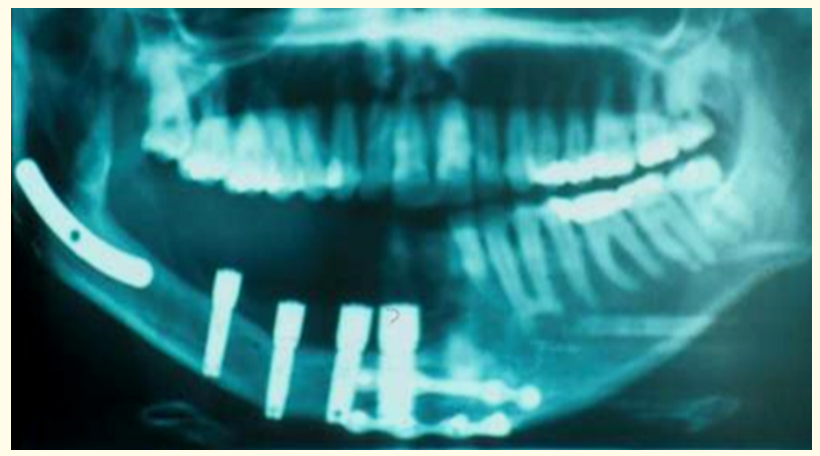

Figure 3: Panoramic radiography, implant installation and Bar de Erich.

Source: Dr. Thais Christina Emidio.

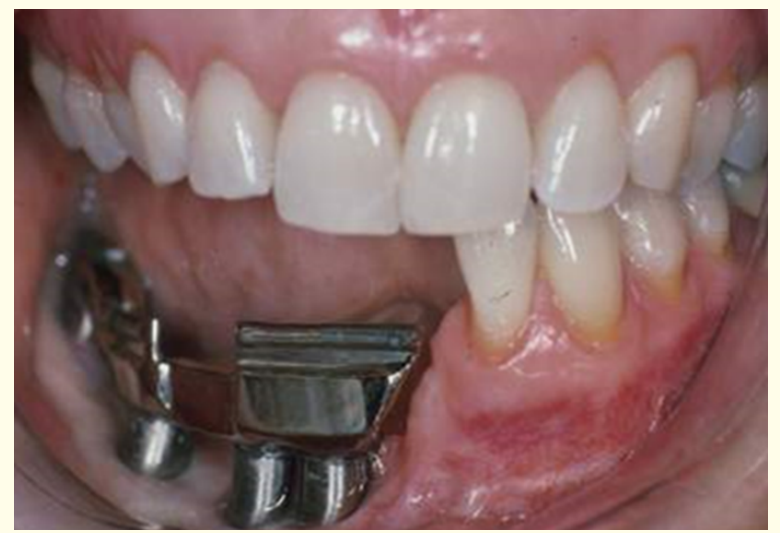

Figure 4: Implants installed in mouth with docking for bar/clip system.

Source: Dr. Thais Christina Emidio.

relapse from the lesion or impaired the summation of the nervous beam. No post-surgical paresthesia was reported to.

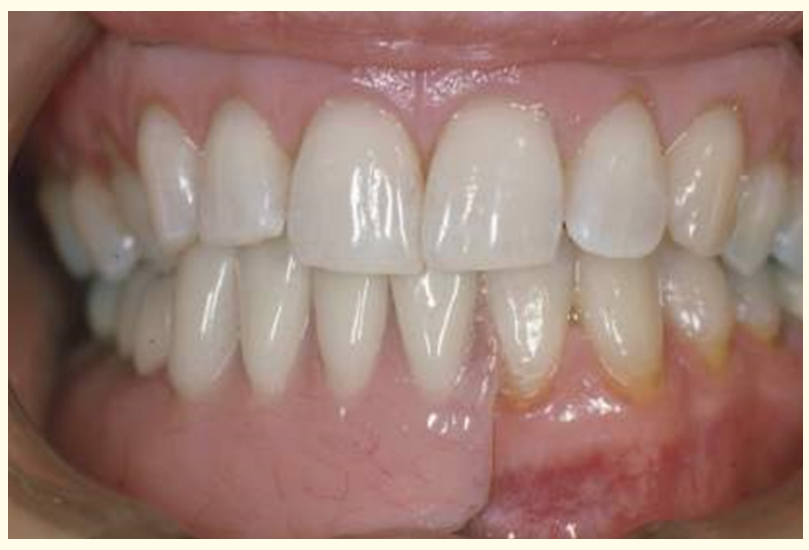

Figure 5: Patient with prothesis installed.

Source: Dr. Thais Emidio. 


\section{Discussion}

The treatment modalities of ameloblastoma are very varied and have been divided into conservative and radical therapies [5]. The curettage technique has shown unacceptable results in relation to high recurrence rates (around 100\%). Curettage in combination with cryotherapy after resection with safety margin in healthy tissue is suitable for eradicating the disease when used as the first treatment option. However, attempts to extend to soft tissue result in necrosis and dehiscence of the wound [31].

The planned treatment for this clinical case was conservative consisting of enucleation of the lesion associated with cryotherapy, following the protocol of Curi, Dib, Pinto [8] which consists of curing the lesion and then freezing the remaining bone through the liquid nitrogen.

The use of liquid nitrogen has been shown to have the ability to devitalize hard and soft tissues in the maxillofacial region. The advantages of cryotherapy are easy application, little discomfort and absence of bleeding. Disadvantages, therefore, include an unpredictable postoperative symptomatology and extensive necrosis at the time of application [30]. In the late postoperative period, pathological fracture of the mandible was observed after unrecommended masticatory exertion. According to Curi, Dib, Pinto [8] the formation of kidnapping, pathological fracture, dehiscence and edema formation have been reported in his studies.

Pathological fracture is a known risk when cryosurgery is applied to the mandible. It appears to be secondary to necrosis and demineralization by weakening the bone, reaching a maximum of 8 weeks after treatment [31]. When bone is weakened by cryotherapy may have the risk of pathological fracture, a phenomenon clinically and experimentally shown by Fisher [28] and Pogrel [32]. Some authors have suggested placing autogenous graft simultaneously in large cavities to promote, as soon as possible, a stimulus in osteogenesis as an attempt to correct the period of bone weakening $[8,30,31]$.

The study by Rosenstein., et al. [18] suggests that cystic ameloblastoma behaves both clinically and biologically as an aggressive tumor. This is based on the high incidence of cortical perforation, dental resorption, lesion size, bone destruction, and many recurrences after enucleation. Based on this data, Salmassy, Pogrel [30], Sampson; Pogrel [31] and Rosenstein., et al. [18] suggest block resection or enucleation and curettage associated with chemical methods, such as liquid nitrogen cryotherapy or Carnoy solution (ethanol and glacial acetic acid, at a volumetric ratio of $3: 1$ ). Reconstruction plate was used in order to have a control of residual mandibular follow-ups. Oliveira Junior, Faber, Mendes, Mendonça, Biscaro (2002) in his studies mention that the reconstruction plate can be used as intermediate use preparing the bed for graft placement and to keep segments stable.

The use of plaques before placement of grafts offers many advantages, such as: if the tumor recicid, identification is easy; if radiotherapy is indicated, radiotherapy can be done safely; and the placement of the graft can be done with plaque on site [33].

\section{Conclusion}

Treatment of ameloblastoma with curettage associated with cryotherapy with liquid nitrogen is a technique that presents very satisfactory results when well indicated.

\section{Bibliography}

1. Adekeye EO. "Ameloblastoma of the jaws: a survey of $109 \mathrm{Ni}$ gerian patients". Journal of Oral and Maxillofacial Surgery 38.1 (1980): 36-41.

2. Lucas Rb. "Pathology of tumors of the oral tissues". $4^{\text {th }}$ Edition. Edinburgh; Churchill Livingstone (1984).

3. Adekeye EO and Lavery Km. "Recurrent ameloblastoma of the maxillofacial region. Clinical features and treatment". Journal of Oral and Maxillofacial Surgery 14.3 (1986): 153-157.

4. Hang Rh., et al. "Reviewing the unicystic ameloblastoma: report of two cases". JADA 121 (1990): 703-705.

5. Bataineh $\mathrm{AB}$ and Jordan I. "Effect of preservation of the inferior and posterior borders on recurrence of ameloblastomas of the mandible". Oral Surgery, Oral Medicine, Oral Pathology, and Oral Radiology 90.2 (2000): 155-163.

6. Nakamura N., et al. "Marsupialization of cystic ameloblastoma : a clinical and histopathologic study of the growth characteristic before and after marsupialization". Journal of Oral and Maxillofacial Surgery 53.7 (1995): 748-754.

7. Zwahlen RA., et al. "Case report: myocardial metastasis of a malignant maxillary ameloblastoma". Journal of Oral and Maxillofacial Surgery 61.6 (2003): 731-734.

8. Curi., et al. "Management of solid ameloblastoma of the jaws with liquid nitrogen spray cryosurgery". Oral Surgery, Oral Medicine, Oral Pathology, and Oral Radiology 84.4 (1997): 339 344.

9. Gomes ACA., et al. "Ameloblastoma: conservative or radical surgical treatment?" Revista De Cirurgia E Traumatologia Buco-Maxilo-Facial 2.2 (2002): 17-24. 
10. Csiba A., et al. "Virus-like particles in a human ameloblastoma". Archives of Oral Biology 15 (1970): 817-826.

11. Gardner Dg and Pecak AMJ. "The treatment of ameloblastoma based on pathologic and anatomic principles". Cancer 46.11 (1980): 2514-2519.

12. Campos GM. "Ameloblastoma fields behavior and histologic paradox: a philosophical approach". Brazilian Dental Journal 1.1 (1990): 5-15.

13. Eversole Ir., et al. "Contemporary oral and maxillofacial pathology". St Louis: Mosby (2004).

14. Neville BW., et al. "Oral and maxillofacial pathology". Rio de Janeiro: Edition. Guanabara Koogan SA (1998).

15. Atkinsonch., et al. "Ameloblastoma of the jaw: a reappraisal of the role of megavoltage irradiation". Cancer 53.4 (1984): 869873.

16. Azoubele., et al. "Ameloblastoma uncystic in jaw - report of a case”. Dental Science Review 24.2 (1997): 215-220.

17. Ackermann GL and Shear MA. "The unicystic ameloblastoma: a clinicopathological study of 57 cases". Journal of Oral Pathology and Medicine 17.9-10 (1988): 541-546.

18. Rosenstein T., et al. "Cystic ameloblastoma - behavior and treatment of 21 cases". Journal of Oral and Maxillofacial Surgery 59.11 (2001): 1311-1316.

19. Laskin DM., et al. "Multilocular lesion in the body of the mandible". Journal of Oral and Maxillofacial Surgery 60 (2002): 1045-1048.

20. Pinsolle J., et al. "Treatment of ameloblastoma of the jaws". Archives of Otolaryngology-Head \& Neck Surgery 121.9 (1995): 994-996.

21. Kim Sg., et al. "Ameloblastoma: a clinical, radiographic and histopathologic analysis of 71 cases". Oral Surgery, Oral Medicine, Oral Pathology, and Oral Radiology 91.6 (2001): 649-653.

22. Nastri Al., et al. "Maxillary ameloblastoma: a retrospective study of 13 cases". British Journal of Oral and Maxillofacial Surgery 33 (1995): 28-32.

23. Yokobayashi Y., et al. "Marsupialization is a possible diagnostic aid in cystic ameloblastoma". Journal of Oral and Maxillofacial Surgery 11.3 (1983): 137-141.
24. Peterson LJ. "Oral and Maxillofacial Surgery Contemporary". Rio de Janeiro. Guanabara Koogan (2000).

25. Gardner DG. "A Pathologist's approach to the treatment of ameloblastoma". Journal of Oral and Maxillofacial Surgery 42.3 (1984): 161-166.

26. Sehdev Mk., et al. "Ameloblastoma of maxilla and mandible". Cancer 33.2 (1974): 324-333.

27. Marcove RC and Miller TR. "Treatment of primary and metastatic bone tumors by cryosurgery". The Journal of the American Medical Association 207 (1969): 1890-1895.

28. Fisher., et al. "The effect of cryosurgery on the strength of bone". British Journal of Oral Surgery 15 (1977): 215-222.

29. Bradley PF. "Modern trends in cryosurgery of bone in the maxillofacial region". International Journal of Oral and Maxillofacial Surgery 7 (1978): 405-415.

30. Salmassy DA and Pogrel MA. "Liquid nitrogen cryosurgery and immediate bone grafting in tyhe management of aggressive primary jaw lesions". Journal of Oral and Maxillofacial Surgery 53.7 (1995): 784-790.

31. Sampson's and Pogrel Ma. "Management of mandibular ameloblastoma: the clinical basis for treatment algorithm". Journal of Oral and Maxillofacial Surgery 57.9 (1999): 1074-1077.

32. Pogrel Ma. "The use of liquid nitrogen cryotherapy in the management of locally aggressive bone lesions". Journal of Oral and Maxillofacial Surgery 51.3 (1993): 269-273.

33. Neville BW., et al. "Oral and maxillofacial pathology". Pennsylvania: WB Saunders Company (1995).

\section{Assets from publication with us}

- Prompt Acknowledgement after receiving the article

- Thorough Double blinded peer review

- Rapid Publication

- Issue of Publication Certificate

- High visibility of your Published work

Website: www.actascientific.com/

Submit Article: www.actascientific.com/submission.php Email us: editor@actascientific.com

Contact us: +919182824667 